decompression, in lieu of tissue removal, a radium tube has been inserted into the substance of the struma and withdrawn after a few hours.

These cases therefore represent some of the more difficult experiences in some of the earlier operations, and the three deaths from meningitis which occurred in this series all followed misdirected operations in cases of this type with a small sella and superimposed tumor. Another patient recovered after a severe meningitis.

In 52 patients a sellar decompression combined with extirpation of tissue or evacuation of a cyst has been carried out 58 times. In these 58 operations there have been 4 operative fatalities: 1 after a primary partial removal of a sellar struma in the case of an acromegalic who had a large intracranial extension of the growth which was unsuspected but which should have been recognized; 2 others after a second attempt to partially remove a large suprasellar tumor from below; and the fourth after a third transphenoidal operation as related. The post-mortem examination in all four of these cases showed that operative relief by the route chosen was utterly impossible and that they were cases suited only for a subtemporal decompression. Thus in the 74 operations in this transphenoidal group there have been 7 fatalities ( 9.5 per cent.), all but one of them occurring in the earlier series.

The results of the transphenoidal operation, which, as has been made clear, is carried out chiefly for the relief of chiasmal involvement, have been most gratifying in the 61 survivors in the 68 cases. Progressively failing vision has become stationary or has been slightly regained over periods varying from a few months to several years in 22 cases. There has been a prompt widening of the fields with marked improvement of vision, often with return to the normal, in another 22 cases. In 2 patients vision was temporarily made worse as a result of the operation, but there was subsequent great improvement. Though vision had been completely lost in 5 cases before the operation, in 2 of the cases it was partially regained. In 8 cases it was unaffected before the operation, and still remains so. In only 3 cases was there a progressive failure of vision despite a successful operation and in all of them the tissues removed showed a malignant transformation of the lesion to which the patients have since succumbed.

The entire operative series for the 95 patients may be tabulated as herewith, 19 of them having been subjected to a decompressive craniectomy in addition to the direct attack on the tumor.

\begin{tabular}{|c|c|c|c|}
\hline \multicolumn{4}{|l|}{ TABULATION } \\
\hline $\begin{array}{l}\text { Subtemporal decompressions } \ldots \ldots \\
\text { Subtemporal explorations } \ldots \ldots \ldots \\
\text { Subfrontal explorations } \ldots \ldots \ldots \\
\text { Transphenoidal decompressions } \ldots \\
\text { Transphenoidal extirpations } \ldots . . .\end{array}$ & $\begin{array}{c}\text { Cases } \\
33 \\
8 \\
5 \\
16 \\
52\end{array}$ & $\begin{array}{c}\text { Operations } \\
37 \\
8 \\
6 \\
16 \\
58\end{array}$ & $\begin{array}{c}\text { Fatalities } \\
2 \\
0 \\
1 \\
3 \\
4\end{array}$ \\
\hline & $\overline{114}$ & $\widetilde{125}$ & 10 \\
\hline
\end{tabular}

Thus there was a total operative mortality of 8 per cent. and a case mortality of 10.5 per cent. Moreover, in the 74 operations in the two transphenoidal groups there have been 7 fatalities ( 9.5 per cent.), most of them occurring in the earlier series.

Thus in these 95 patients there have been 125 operations, with 10 fatalities -8 in my earlier Baltimore series of 74 operations ( 10.8 per cent.), 2 in my subsequent Boston series of 50 operations ( 4 per cent.), showing a lowering of the mortality with a wider experience.
That these mortality figures can be further improved with increased familiarity in the proper selection of cases and with perfected operative methods is evidenced by the fact that in the last 33 transphenoidal operations there has been only one death, this having occurred in the case of the patient in whom, as recorded, a third operation was unwisely undertaken.

Statistics are dreary matters but it is periodically incumbent upon us to assemble our cases not only for our own instruction lest we bury in obscurity our mistaken and bad results, but also to acquaint others with the standing of operative measures.

We have become confronted of late years with new surgical problems relating to a group of patients with disorders which were unrecognized by our forebears, and hesitating as our steps may be in meeting these problems our operative experiences must from time to time be recorded in all their lights and shadows.

The Peter Bent Brigham Hospital.

\section{TWO NEW METHODS OF CLOSURE OF THE PYLORUS FOR PYLORIC AND DUODENAL ULCER *}

\section{ALFRED A. STRAUSS, M.D. CHICAGO}

Closure of the pylorus for pyloric and duodenal ulcer has been recognized more and more in recent years as of the greatest importance in the cure of pyloric and duodenal ulcer. Prominent among the investigators and surgeons who have demonstrated various methods are Kelling, who, in 1900, used a silk ligature, and Parlavecchio, who, in 1910, used a ligature of cotton and wool, which was tied around the pylorus only tight enough to bring the mucous membrane into apposition. This was insufficient in both man and animals, the ligature cutting through, leaving the lumen of the pylorus the same as before operation. In addition, patients operated on by this method suffered severe gastric pain. Bier modified this method by crushing the portion of the stomach where the ligature was placed. He claimed that these patients have no pain. Closure is not complete, but adequate clinically. In 1913, at the German Surgical Congress, he stated that he is dissatisfied with all methods of closure, and now has returned to the use of the simple ligature, by simply infolding the ulcer with sutures, after the method of Moynihan. This is not a complete closure, but it suffices. Mayo and Moynihan used the puckering-string method. The ligature passes only through the muscularis, in order to infold the mucosa. Both here and in England good results have been obtained by this method. Küttner and Körte have both had success and failure, and in animals no lasting stenosis is accomplished.

Körte used puckering sutures both on the anterior and posterior walls, whenever possible. If perigastric adhesions are present, then it suffices to place them in the anterior wall only. This does not give a complete closure, as is shown on the cadaver by passing the finger into the stomach after ligatures are applied.

Girard and Doyen performed a pyloroplasty at right angles to the usual direction, which narrows instead of

* Additional illustrations appear in the author's reprints.

* From the Department of Experimental Surgery of the Morris I:1stitute of Medical Research of the Michael Reese Hospital. 
widening the lumen. They cut down to the mucosa only. Propping reported failures by this method.

Bogoljuboff and Wilms used the fascia lata and anterior sheath of the rectus. This method seemed an improvement over all other methods. Wilms had used it in twelve cases at the time of the German Surgical Congress in 1913. The patients had no blood in the

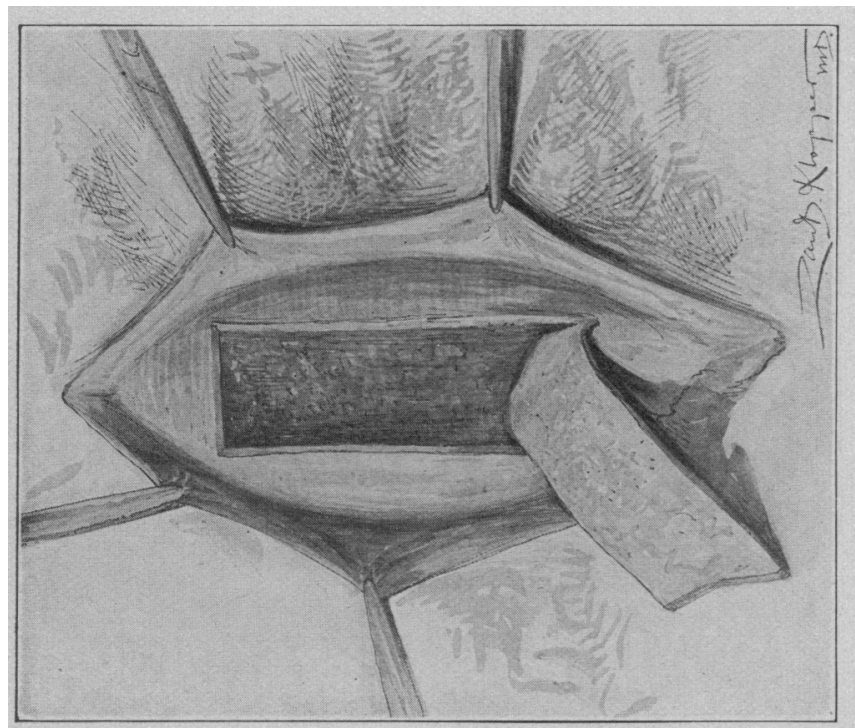

Fig. 1.-First method of pyloric closure. Anterior sheath of rectus exposed and flap resected.

stools and no pains. The Roentgen ray showed closure to be complete, the stomach emptying itself in one hour. In three other cases Wilms used omentum. These were also reported as successful. Siegel, however, reports a complete failure by this method, and after two months no trace of the fascia was demonstrable. Bier reports a case of enormous scar formation and perigastritis by this procedure.

Brewer used an aluminum band $1 \mathrm{~cm}$. in width and $5 \mathrm{~cm}$. in length. This was placed around the pylorus

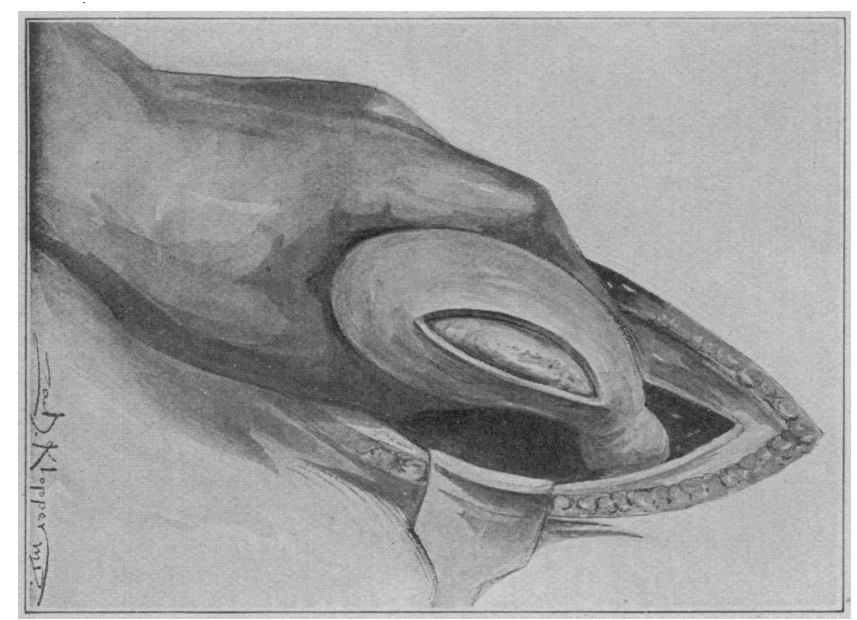

Fig. 2.-Incision in stomach to pyloric sphincter, exposing mucosa.

and rolled snugly with the fingers to produce sufficient compression to obliterate the lumen. He reported experiments on nine animals, the oldest of which was 9 weeks, in which the pylorus was closed.

Bartlett divided the muscular coats and mucosa by means of a metal skewer. This is thrust directly through both walls of the stomach into the lesser peri- toneal cavity, and out again. A clamp is placed behind the skewer and several mattress sutures introduced between skewer and clamp. This embraces the whole thickness of both walls of the stomach. The skewer is cut out with a sharp knife and the mattress sutures tied. A hemostatic running stitch of silk or linen unites the four exposed cut edges. The ridge of tissue formed by the mattress sutures is inverted with a continuous Lembert row.

Von Eiselsberg's unilateral exclusion of the pylorus is the most exact method. It would be recommended in all cases were it not a relatively long operation, producing a great deal of shock. The exclusion is a larger operation than the gastro-enterostomy itself, and almost impossible to perform when dense adhesions are present. Henle, who otherwise recommends it, lost 16.65 per cent. with exclusion, versus 6 per cent. with gastro-enterostomy alone. A fair number of cases of fatal hemorrhage have been reported following this operation.

While I was carrying on my work, Biondi published, in October, 1913, a method of pyloric closure. The first step, which is shelling out the membrane, is prac-

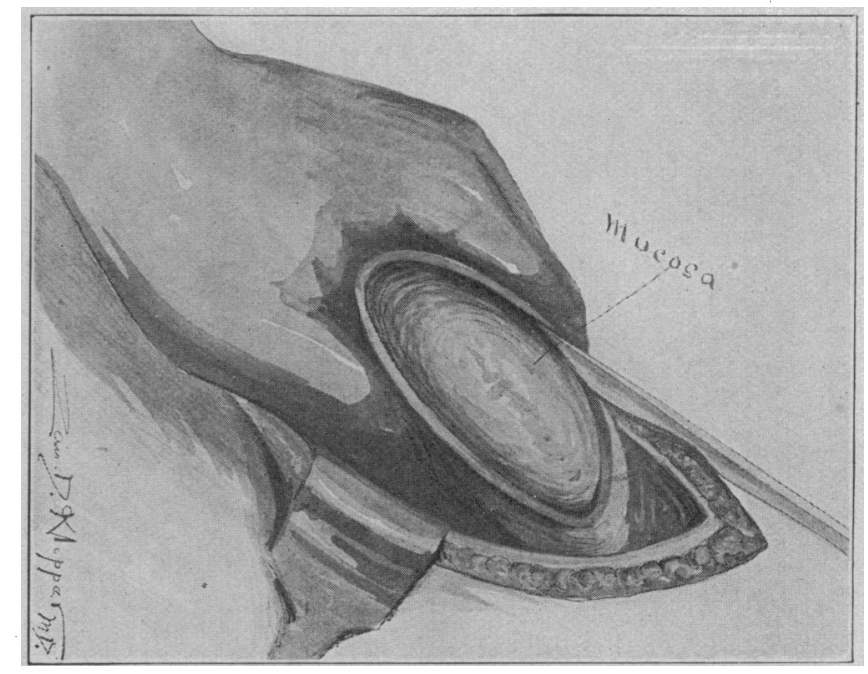

Fir. 3.-Method of freeing mucosa.

tically the same as one of the methods to be described here, but the second step, producing closure, is entirely different, both in method and in principle. He divides the shelled-out membrane, making a closed cuff at each end with sulk sutures.

It will be noticed from the foregoing that the methods can be divided into two great classes: First, those which attempt to close the pylorus by bringing the mucosa into apposition with ligature, puckering string, fascia and metal band. Second, those which divide the mucosa alone or mucosa and muscularis. The ligature method is bound to fail at all times, because no ligature can be buried, especially near the pylorus, where the peristaltic waves are most powerful. The ligature produces an anemic necrosis, and sloughs inward toward the lumen of the bowel. I believe there are two important factors which explain this. First, the force of the action of the peristaltic wave of the stomach is toward the central portion of its lumen; consequently any ligature or object which produces an anemic necrosis will be forced inward. The intraabdominal pressure possibly is a factor. We know that in the normal collapsed stomach intra-abdominal 
pressure far exceeds the pressure within the gastric cavity. This gives additional force to bodies in the wall of the stomach, causing them to be forced in the direction of least resistance, namely, its lumen.

Placing fascia around the muscularis of the pylorus has the disadvantage of having to overcome the powerful peristaltic contractions, the occurrence of adhesions and the possibility of absorption.

The second class, which divides the mucous membrane or mucous membrane and muscularis, has a fair amount of success. The ligatures which close the mucosa slough inward, as is well known in gastroenterostomy. If this occurs at both divided ends at the same time, it leaves a communication. It is also a well-established fact that all physiologic tubesstomach, bowel, ureter, common bile duct - if given the slightest chance, have an inherent tendency to reestablish their mucous lining and lumen.

Taking advantage of the above facts, that the mucous membrane of the stomach, when divided, has a tendency to reestablish its lumen, and that ligatures are always forced toward the lumen of the bowel, I tried to keep this work within the limits of the fol-

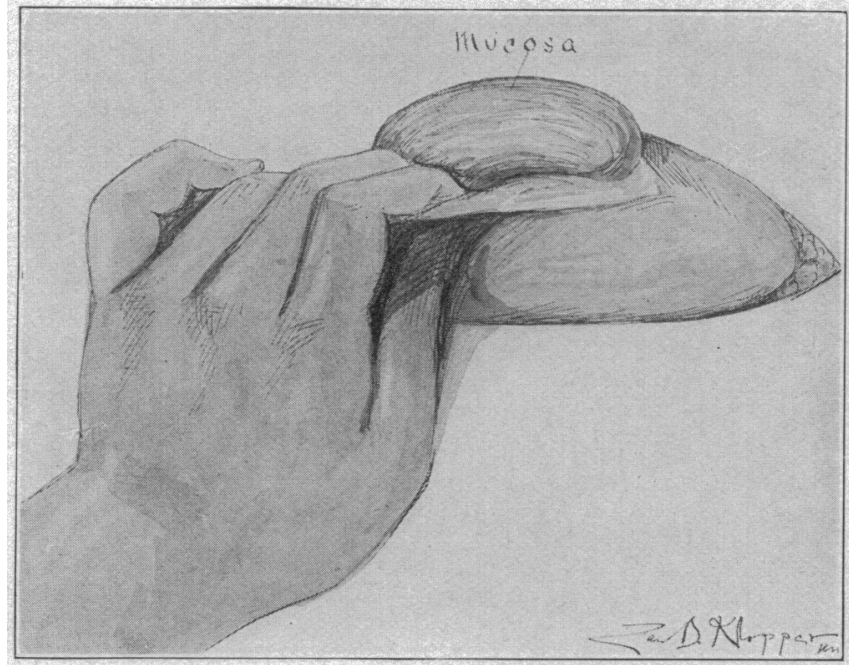

Fig. 4.-Muscularis everted, mucosa lying on its surface.

lowing principles: First, the closure must be accomplished without division of the mucous membrane, but rather a closure produced by connective tissue contractions, such as one finds in the stricture of the bowel and hour-glass stomach. Second, the operation should be a simple one, which can be done in a short time, so as not to add too much additional shock to the necessary operation of gastro-enterostomy.

\section{AUTHOR'S FIRST METHOD}

With the above facts in mind the following surgical procedure was carried out:

A right rectus incision was made $1 / 2$ inch to the right of the midline, extending from the angle of the ribs down to the umbilicus. The anterior sheath of the rectus was exposed and a flap resected, $3 / 4$ by $11 / 2$ inches (Fig. 1). In resecting this a thin, adherent layer of muscle fibers from the rectus muscle was taken with it. The stomach was next brought into view. The pyloric portion was then tightly grasped between the thumb and index finger. An incision was then made proximal to the pyloric sphincter on the upper outer surface $1 \mathrm{t} / 2$ inches in length (Fig. 2). This exposed the mucosa. Two strokes with the scalpel on each side, between the mucosa and muscularis, freed the mucosa sufficiently (Fig. 3), so that the thumb could be placed under the pylorus and, grasping the edge of the muscularis, the entire muscularis could be everted (Fig. 4), so that the mucosa lay on the everted muscularis like a rubber tube. This step is the most important one. Without eversion it is next to impossible to separate the mucosa from the muscularis without

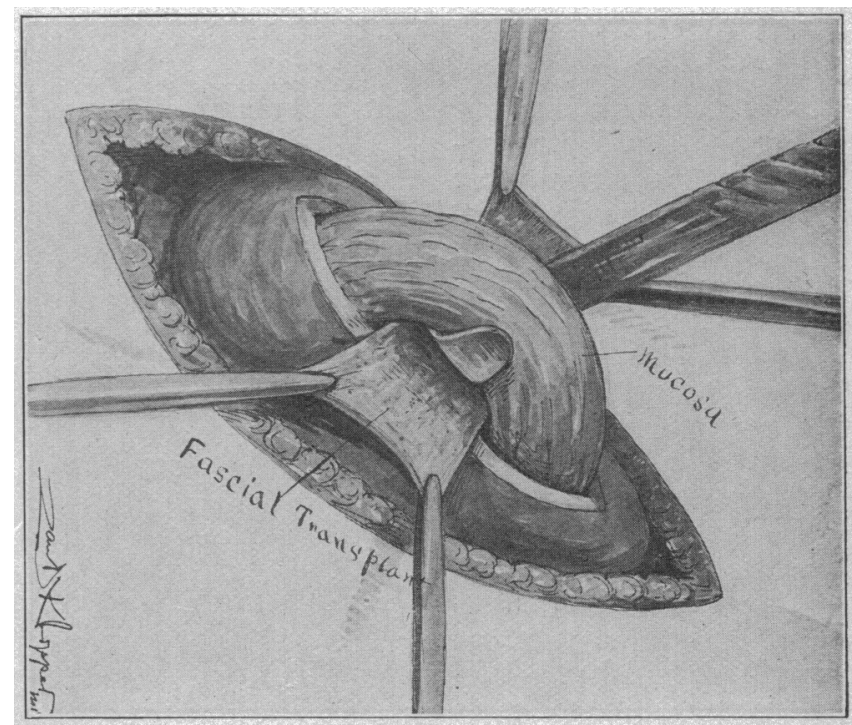

Fig. 5.-Free fascial transplant from rectus placed around mucosa.

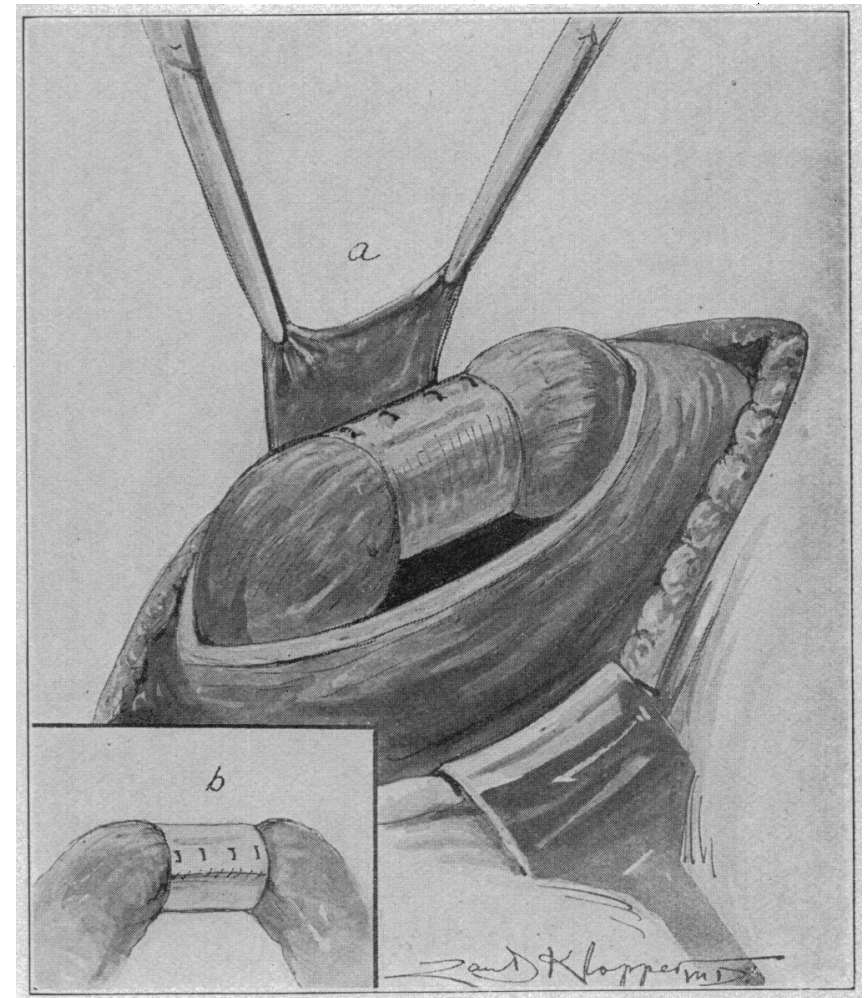

Fig. 6.- $a$, End of transplant sutured to mucosa and traction being made to cause collapse of mucosa; $b$, final suturing of end of transplant. Note double suturing.

tearing it. It can now be easily separated with a sharp scalpel. There is only a small amount of oozing of blood.

The free fascial transplant of the rectus was placed around the mucosa (Fig. 5). One end of this transplant was sutured with four interrupted sutures to the mucosa (Fig. 6, a); on the other end traction was made, which collapses the mucosa and rotates it about one-eighth of a turn on its longitudinal 
axis. This aids in making it a complete closure. The end of the transplant was sutured with four interrupted sutures to the surface of the attached portion, just tightly enough to hold it in a collapsed condition, and a third continuous suture holding down the edge (Fig. 6, a).

The mucosa was now replaced in its normal position within the muscularis and was closed by continuous interlocking sutures, as in Figure 7, two of the sutures catching the fibrous band so that it cannot slide forward and backward on the inner surface of the musculatis.

I have performed this closure at the junction of the fundus of the stomach with the antrum pylori as well as near the sphincter pylori, in order to show that ulcers in the antrum pylori as well as duodenal ulcers could be shut off by this method. The suture material used was No. 2 braided waxed silk. The procedure takes fifteen minutes-five minutes for shelling out the mucosa, five for placing on the transplant and three to five for closing the musculature. In seven cases the anterior sheath of the rectus was used; in five cases the transversalis fascia, muscle and peritoneum and in four cases fascia lata.

The gastro-enterostomy was performed in the us'tal manner, with the exception that the anastomosis was placed on the posterior wall as near the closed pylorus as possible. It seems when the anastomosis is made at the most dependent portion of the greater curvature, on the posterior wall, the stomach empties quickly up to the point of anastomosis and then leaves a residue of food between the pylorus and the anastomosis for hours.

In August, 1913, I first started on this procedure, but, owing to an epidemic of distemper, almost all dogs operated on died within a few days following the operation. After the epidenic subsided,

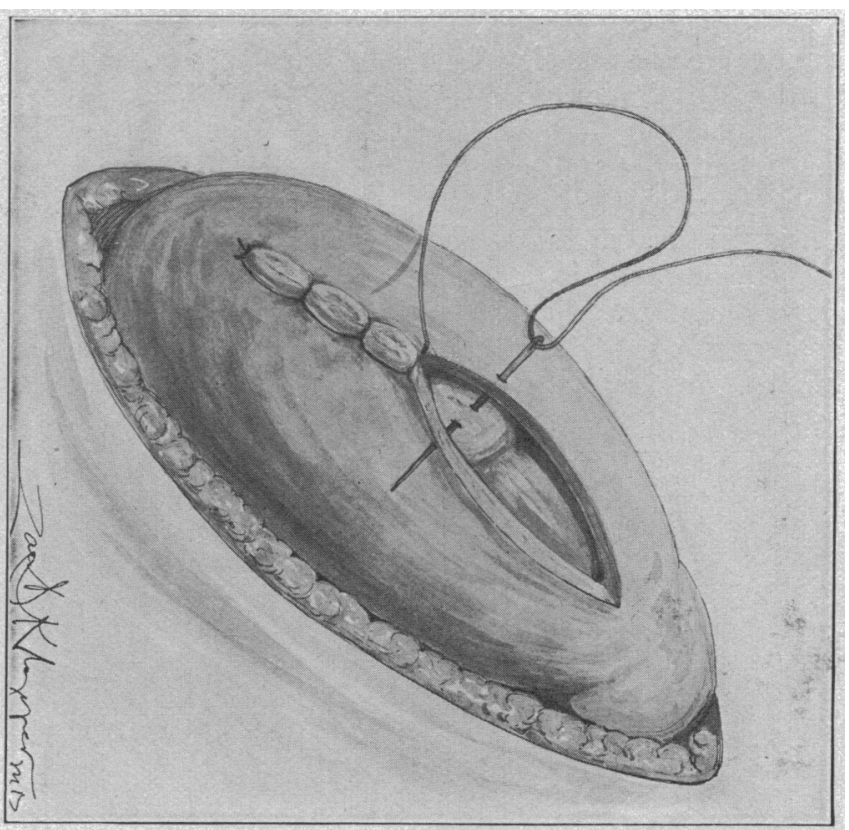

Fig. 7.--Mucosa replaced in normal position and closed by interlocking sutures. Note catching of fibrous band in sutures to prevent slipping.

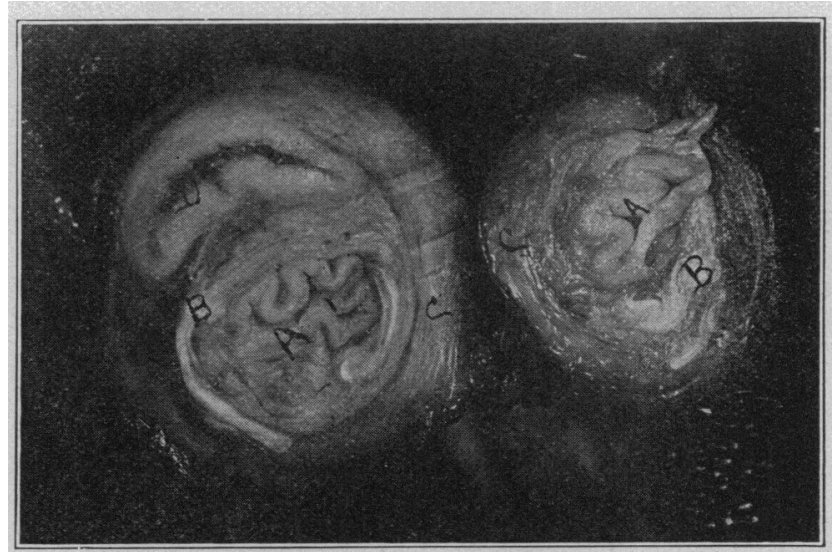

Fig. 8.-Cross-section of closed antrum of the pylorus. From a photograph. $A$, mucosa; $B$, fascial transplant holding mucosa; $C$, muscularis of pylorus; $D$, blind fold of mucoss at upper end of closure outside of fascial transplant. junction of the antrum pylori and fundus of stomach. Necropsy showed the stomach and pylorus perfectly free. On examining the pylorus one would not know that the operation had been performed on it. The stomach was removed, the gastroenterostomy clamped off, and the esophageal end of the stomach attached to a hydrant. Under enormous hydrostatic pressure not a drop of water could be forced through the pylorus. The pylorus was sectioned and the water test again performed, with the same result. The cross-section of the closed pylorus (Fig. 8) showed the mu cos a firmly collapsed. Arolind it, the free transplant could be distinctly seen attached to the mucosa on one side, and on the other side to the muscularis. The muscularis appeared perfectly normal.

Histology. - Complete cross-section (Fig. 9) of the pylorus shows the mucosa normal and collapsed, with no sign of pressure atrophy in any portion of it. Around it is seen the fascial transplant perfectly organized and containing many small bloodvessels attached to the mucosa. The striated muscle fibers from the rectus also appear normal, still retaining their nuclei. The muscularis is attached to the fibrous transplant, and shows no changes.

In Figure 10 is shown a section of the fibrous band under high power. The glands of the mucosa appear normal. The fascia is intimately connected to the latter. In it are many bloodvessels and nuclei. The muscle fiber's of the rectus sheath also appear to be normal.

At the end of four months six animals were killed. The changes were the same as noted above. All of them showed an absolutely watertight pylorus. Three of the dogs had a few web-like adhesions from the sutures of the pylorus to the under surface of the liver. At the end of five months four more were killed, with the same findings. At the end of six sixteen dogs were operated on by the above procedure, and practically all of them made uneventful recoveries. None of the dogs vomited following the operation, and all were placed on a full diet within six days. They all appeared in perfect health and many of them gained in weight. At the end of two months the first animal was roentgenographed and fluoroscoped and then killed. The roentgenogram showed the pylorus absolutely closed and the gastro-enterostomy working. In this dog the closure was performed at the months two more were killed, with the same findings. In one of these the closure was made proximal to the sphincter pylorus, and the transplant used was peritoneum, transversalis fascia and transversalis muscle. On cross-section the mucosa is collapsed and around it. can be seen the fascial band. The muscularis appears normal. Histologic examination shows, on complete cross-section, that the transversalis muscle, but the white fibers of the transversalis fascia seemed to be perfectly organized, as in the specimen described above. peritoneum had disappeared and little could be seen of the 
My reason for taking this particular transplant of peritoneum, transversalis fascia and muscle was that my recent work on artificial ureter $^{1}$ made from this particular transplant showed a complete metaplasia, the fascia being transformed into a bony plate. No such metaplasia occurred when placed around the

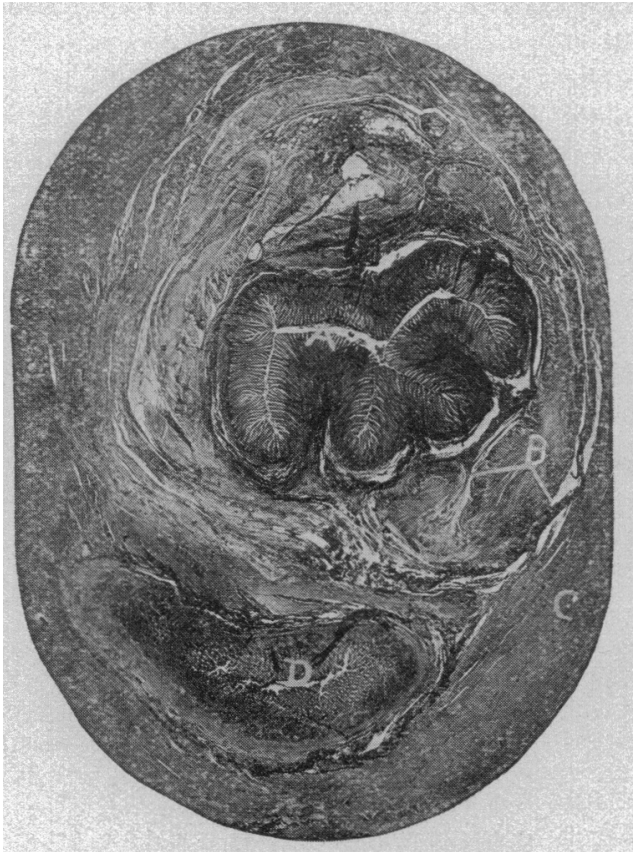

Fig. 9.-Cross-section of portion of pylorus shown in Fig. 8. From a photomicrograph $\times 5.5 ; \mathrm{A}$, collapsed mucosa; $\mathrm{B}$, fascial transplant around mucosa; C, muscularis; $\mathrm{D}$, blind fold of mucosa. the sphincter pylori. The effect was funnel-shaped, thus preventing the abrupt cutting off of the peristaltic waves. The ribbon sutured in this manner was just tight enough to place the mucosa in apposition. The tissues covering the ribbon contract down on it still tighter, making the closure still more complete. This method is very simple and takes only five minutes.

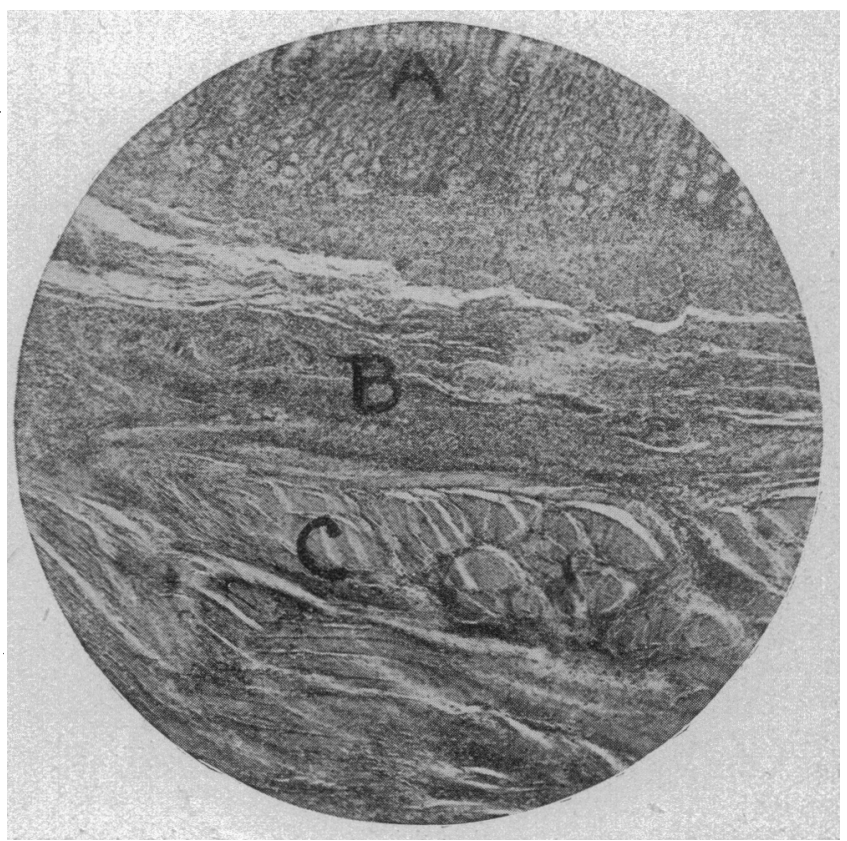

Fig. 10.-Section of portion of pylorus shown in Fig. $\mathrm{S}$. Frum a photomicrograph; A, mucosa; B, connective tissue of transplant; $C$. muscle fibers of transplant.

mucosa of the pylorus, showing that the metaplasia which did occur was due to the chemical constituents of the urine.

\section{AUTHOR'S SECOND METHOD}

The second or silk-ribbon method was based on two facts: (1) ordinary ligatures cut through the pyloric musculature, and (2) fascial transplants placed around the pylorus have a tendency to give way under the powerful peristaltic contractions. Furthermore, these transplants become adherent to adhesions or disappear entirely. To overcome these obstacles a piece of ordinary white silk ribbon $3 / 4$ inch in width was sterilized. A closed Kocher forceps was passed beneath the pylorus ihrough the mesentery. The forceps was next opened to enlarge the mesenteric opening and the ribbon pulled through (Fig. 11, a). One



Fig. 11.-Silk ribbon method; $a$, ribbon pulled through mesenteric onening; $b$, end of ribbon sutured to muscularis; $c$, final suturing of ribbon. end of the ribbon was sutured witk four interrupted sutures to the muscularis, as in Figure $11, b$. The other end was sutured to the ribbon with four interrupted sutures, and the edge with continuous sutures (Fig. 11, c). The sutures near the antrum pylori were not placed as tightly as those near

1. Strauss, A. A.: Surg., Gynec. and Obst., January, 1914.
Twelve dogs were operated by the above method. One animal tore open its abdomen at the end of one week. Another died of peritonitis, the cause of which could not be ascertained. The other ten made uneventful recoveries. At the end of five days one dog was killed. The tissues from the lesser omentum had covered the ribbon completely, as in Figure 12. At the end of four weeks one dog was killed, showing the same findings. At the end of two months four more dogs were killed, with the same findings. In one of these the ribbon was placed more tightly than usual, and cut only a small way into the tissues. At the end of five and one-half months three more animals were killed. In these the ribbon was covered by a glazed, transparent tissue, as in Figure 13. The pylorus in two was perfectly free, while in the third quite dense adhesions were formed between the pylorus and the liver. All of these stomachs were put to the water test, and the pylorus found absolutely closed. 
In six additional dogs a rubber ribbon was used instead of silk ribbon, the rubber being impregnated with 15 per cent. sulphur. All of these animals, with the exception of one, died in from five to eight days following operation, the constant contractile power of the rubber cutting through the pylorus. One animal lived, and was killed at the end of two months. It showed the same results as with the silk-ribbon

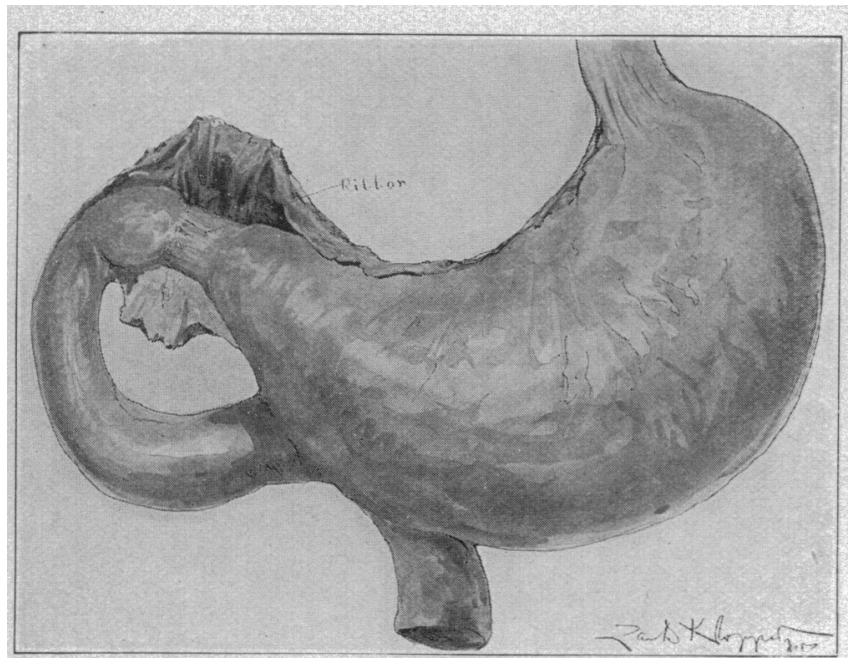

Fig. 12.- Stomach from dog killed five days after operation. Ribbon completely covered by tissues from lesser omentum.

method, only here under high pressure the pylorus was not water-tight.

\section{CONCLUSIONS}

1. In the sixteen dogs operated on by the submucous transplant method, the pylorus was watertight under hydrostatic pressure, and as shown by fluoroscope and roentgenogram. The free fascial transplant became organized with the mucosa and muscularis in every instance, producing sufficient contraction to hold the pylorus closed without producing

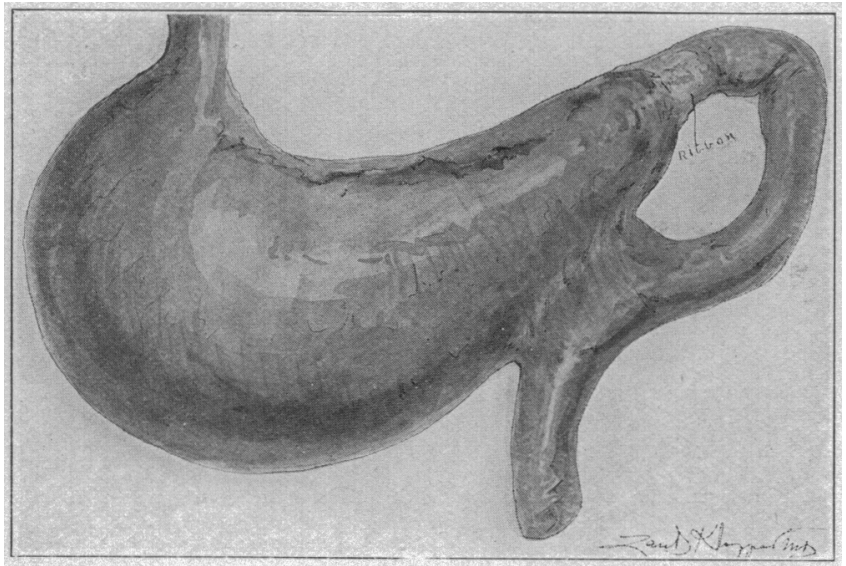

Fig. 13.-Stomach from dog killed five and one-half months after operation. Ribbon covered by glazed transparent tissue.

any necrosis of mucosa. This I believe is due to the fact that the connective tissue used is placed under a tension similar to what it would be in the anterior sheath of the rectis.

2. The free transplant placed between the mucosa and muscularis has the advartage of not having to overcome the powerful peristaltic contractions of the pyloric musculature, and is not subject to the forma- tion of adhesions and inflammatory changes, as a transplant placed around the musculature of the pylorus would be.

3. The method of shelling out the mucosa is safe, in that there is no danger of hemorrhage from large vessels, and less danger from infection, as in the methods by which the mucosa has to be divided.

4. The silk-ribbon method, while it is very simple and produces a perfect closure, and while the number of experiments seems to show it to be a fairly safe method, has the objection of having a large foreign body buried. Of the two methods the transplant method is by far the one of choice. The rubber method I would consider dangerous and a failure.

I want to thank Dr. E. Kirk of the Morris Institute of Medical Research for the valuable advice he has given me while carrying on this work, and Miss Wilton who assisted me in the operative technic.

30 North Michigan Boulevard.

\section{THE RESULTS IN ONE HUNDRED OPERA- TIONS PERFORMED ON THE DIAG- NOSIS OF BRAIN TUMOR*}

HERMANN KÜTTNER, M.D.

Professor of Surgery, Schlesische Friedrich-Wilhelms-Universität

BRESLAU, GERMANY

The firm confidence with which the experienced surgeon of the present day approaches the solution of the problems set before him suffers a severe setback when these involve the operative treatment of brain tumors. True, we frequently read of single successful operations, but the infinite measure of our failures becomes apparent only in a few larger statistics. In no other domain of surgery are we so much at the mercy of the treacherous patient. None of us have been spared annoying surprises and numerous disappointments. And yet, when we glance back at what has been achieved at operations performed on the diagnosis of brain tumor, we need not abandon ourselves to too pessimistic a view of our accomplishments. We should always bear in mind that, without operation, the patients progress toward a terrible fate - excruciating headaches, epileptic attacks, paralysis, and chiefly, steadily advancing blindness which renders lif no longer worth the living for these unfortunates. And here we find the explanation why we never encounter serious difficulties in obtaining the consent to operation on the part of the patients themselves, or of their relatives, although they have been made familiar with its dangers.

The results of operations for brain tumor wiil always depend on the certainty of diagnosis and the peculiarity of each particular case. The relatively large number of our decompressions demonstrate that impossibility of localizing the process, or of determining its extent, only too often frustrates radical operation and, with it, a permanent resuit. Much could be improved if brain-tumor suspects were only brought under competent neurologic observation early in the disease. I am very well aware of the difficulties of a diagnosis of brain tumor in the beginning of the affection.

* Read before the Secticil on Surgery, General and Abdominal, at the Sixty-Fifth Annual Session of the American Madical Association. Atlantic City, N. J., June, 1914. 